\title{
Temporal trends in the healthy soldier effect in a cohort of Royal Norwegian Navy servicemen followed for 67 years
}

\author{
Leif Aage Strand (1) , ' Jan Ivar Martinsen, ${ }^{2}$ Elin Anita Fadum, ${ }^{1}$ Einar Kristian Borud ${ }^{1,3}$
}

\begin{abstract}
- Additional material is
published online only. To view please visit the journal online (http://dx.doi.org/10.1136/ oemed-2020-106475).

${ }^{1}$ Norwegian Armed Forces Joint Medical Services, Institute of Military Medicine and Epidemiology, Norwegian Armed Forces, Ullensaker, Norway

${ }^{2}$ Institute of Population-based Research, Cancer Registry of Norway, Oslo, Norway ${ }^{3}$ Department of Community Medicine, UiT The Arctic University of Norway, Tromso, Norway
\end{abstract}

\section{Correspondence to}

Dr Leif Aage Strand, Norwegian Armed Forces Joint Medical Services, Institute of Military Medicine and Epidemiology, Norwegian Armed Forces, Ullensaker, Norway; laastrand@forsvaretshelser egister.no

Received 10 February 2020 Revised 27 May 2020 Accepted 4 June 2020 Published Online First 1 July 2020

\author{
ABSTRACT \\ Objectives To investigate temporal trends in the \\ 'healthy soldier effect' (HSE) among 28300 Royal \\ Norwegian Navy servicemen who served during \\ 1950-2004.
}

Methods Standardised mortality ratios (SMRs) for all causes, diseases and external causes were calculated from national rates for the entire study period (19512017), and for seven successive follow-up periods after the first recorded day of Naval service, for the overall cohort and for two subgroups: land-based personnel and vessel crews. Poisson regression, expressed as rate ratios, was used to compare all-cause mortality between the subgroups.

Results In the overall cohort, SMRs for all-cause mortality increased steadily during the first six 10-year follow-up periods, from 0.52 to 0.94 , which was still lower than national rates. After 60 years, the lower mortality compared with national rates was no longer statistically significant ( $S M R=0.93)$. Low non-neoplastic disease mortality contributed most to the longevity of the only for the first and third 10-year follow-up periods. External-cause mortality rose to national rates after 40 years. An HSE was present among vessel crews, but their total mortality rate was $24 \%$ higher than that among land-based personnel, who also showed a longer-lasting HSE.

Conclusions The HSE eroded gradually over time but was still present at 60 years of follow-up for all-cause mortality. The effect was strongest and most long-lived for non-neoplastic disease, lasted up to 40 years for external causes, and was relatively short for cancers. Land-based personnel showed stronger and longerlasting HSE than vessel crews. HSE. For neoplastic diseases, there was a mortality deficit

\section{Key messages}

What is already known about this subject?

- Several studies have shown that military personnel exhibit a 'healthy soldier effect' (HSE) in terms of lowered mortality when compared with the general population, but there is little information on how long this effect lasts. The longest lasting HSE described in the literature was still apparent after 30 years of follow-up.

\section{What are the new findings?}

- We followed a cohort of Royal Norwegian Navy servicemen for mortality over seven successive follow-up periods covering more than 60 years after the first recorded day of Naval service

- The HSE eroded gradually over time but was still present at 60 years of follow-up for allcause mortality. The effect was strongest and most long-lived for non-neoplastic diseases, for which the HSE still persisted after 60 years. The HSE lasted up to 40 years for external causes, but was relatively short for cancers.

- Land-based Navy personnel showed stronger and longer-lasting HSE than vessel crews.

How might this impact on policy or clinical practice in the foreseeable future?

- The HSE can probably be attributed to the medical selection that takes place before and during military service and a demand to stay physically fit during service. However, some effort should be made to further investigate the observed difference between land-based personnel and vessel crews, as both lifestyle factors and occupational exposures inside and outside the Navy might play a role.

\section{INTRODUCTION}

Working populations often show lower mortality rates when compared with general populations. This is mainly due to selection in employment based on good health. This effect is known as the 'healthy worker effect', a term that was first used by McMichael et al. ${ }^{1}$ The military equivalent of this phenomenon, the 'healthy soldier effect' (HSE), has frequently been observed in cohorts of deployed and non-deployed soldiers. ${ }^{2-10}$ The HSE can probably be attributed to the medical selection that takes place before and during military service, a demand to stay physically fit during service, and, in some countries, better access to medical services during and after service. ${ }^{2}$

The question of interest is how long the HSE lasts. Several studies have indicated that such effects decline over time. Fox and Collier calculated allcause mortality in successive 5 -year periods since the first day of employment among British industry workers. They observed a mortality rate as low as $37 \%$ of the expected rates in the first 5 -year period, but the effect almost disappeared after 15 years of follow-up. ${ }^{11}$ A systematic review which aimed to quantify the HSE showed that the military cohort 
with the largest mortality reduction had the shortest follow-up period (2.4 years). ${ }^{34}$ A group of US Army veterans from the Second World War followed from 1947 showed an HSE that was still present after 20 years of follow-up. The authors noted that the HSE varied by the cause of death; it was absent for external-cause mortality and was present only during the first 5 years for neoplasms. ${ }^{12}$ The same pattern was observed in a cohort of Norwegian peacekeepers deployed to Lebanon during 1978-1998, ${ }^{13}$ while HSE for non-neoplastic diseases was present after 15 years of follow-up (unpublished data). Waller and McGuire followed cohorts of Australian war veterans for successive 10-year intervals up to $30+$ years (Vietnam War veterans) and $40+$ years (Korean War veterans) from their return from deployment. Temporal patterns of HSE varied by study cohort and by cause of death. For all-cause mortality, the HSE was absent among Korean War veterans and among Vietnam War regular Army veterans, but it lasted up to 30 years among Vietnam War national service Army veterans. In a comparison cohort consisting of Army servicemen who completed their service in Australia only, the HSE was still present after 30 years of follow-up. As the majority of the members of this cohort were under 56 years of age at the end of follow-up, the authors stated that further follow-up may be necessary to observe the point at which the HSE is no longer present. ${ }^{5}$

The first author of our study previously reported on causespecific mortality and cancer incidence in a cohort of 28300 Royal Norwegian Navy servicemen who served after the Second World War. The study found an HSE for mortality from all causes, external causes, and non-neoplastic diseases such as diseases of the circulatory system, respiratory system and digestive system, but not for cancer, during the overall follow-up (1951-2007). However, when the cohort was divided into two subgroups according to duty station (land-based personnel and vessel crews), the HSE was present but at a statistically significant, lower rate in vessel crews than in their land-based peers. ${ }^{6}$ We have extended the follow-up of this cohort by 10 years in an attempt to investigate temporal trends in HSE over seven successive time periods during the up to 67-year follow-up in the overall cohort and in the two duty station subgroups. Studies that follow military personnel into old age are important in order to provide a more comprehensive picture of how military people manage through life after service. The results may aid to point at risk factors that manifest many years after service, and may tell if military personnel are more or less susceptible to risks that usually occurs in old age compared with the general population.

\section{MATERIAL AND METHODS Study population}

This study cohort was established from the military personnel database and paper service history files, as described in Strand et $a l,{ }^{14}$ and consists of 28349 servicemen-commissioned officers (42\%), non-commissioned officers and petty officers (33\%), and enlisted personnel (25\%)-who served in the Royal Norwegian Navy at some time between 1950 and 2004. Servicemen were divided into two subgroups according to duty station: personnel who never served aboard a vessel (land-based personnel) and personnel who ever served aboard a vessel (vessel crews). The subgroups consisted of 12943 (46\%) and 15406 (54\%) servicemen, respectively (table 1 ).

\section{Follow-up for incident deaths}

Information on date and underlying cause of death was retrieved by linkage to the Norwegian Cause of Death Registry, which is

\begin{tabular}{|c|c|c|c|}
\hline Characteristics & \multirow{2}{*}{$\begin{array}{l}\text { All } \\
n=28349 \\
(100 \%)\end{array}$} & \multirow{2}{*}{$\begin{array}{l}\text { Land-based } \\
\text { personnel, } n=12 \\
943(100 \%)\end{array}$} & \multirow{2}{*}{$\begin{array}{l}\text { Vessel crews, } \\
n=15406 \\
(100 \%)\end{array}$} \\
\hline Cohort & & & \\
\hline Died during follow-up & $6191(21.8)$ & $2494(19.3)$ & $3697(24.0)$ \\
\hline Emigrated during follow-up & $940(3.3)$ & $428(3.3)$ & $512(3.3)$ \\
\hline Year of birth, range & $1883-1985$ & 1883-1985 & 1893-1985 \\
\hline Year of birth, median (IQR) & $1953(26)$ & $1954(25)$ & $1952(26)$ \\
\hline \multicolumn{4}{|l|}{ Year of start of service } \\
\hline$<1951$ & $2033(7.2)$ & $874(6.8)$ & $1159(7.5)$ \\
\hline 1951-1959 & $4274(15.1)$ & $1646(12.7)$ & $2628(17.1)$ \\
\hline 1960-1969 & $6455(22.8)$ & 3018 (23.3) & $3437(22.3)$ \\
\hline 1970-1979 & $4767(16.8)$ & $2327(18.0)$ & $2440(15.8)$ \\
\hline 1980-1989 & $5470(19.3)$ & $2607(20.1)$ & $2863(18.6)$ \\
\hline 1990-1999 & $4285(15.1)$ & $2070(16.0)$ & $2215(14.4)$ \\
\hline 2000-2004 & $1065(3.8)$ & $401(3.1)$ & $664(4.3)$ \\
\hline Years of Navy employment, average & 6.2 & 4.4 & $7.8\left(3.0^{*}\right)$ \\
\hline Age at start of follow-up, range & $15-69$ & $15-69$ & $15-58$ \\
\hline Age at start of follow-up, median (IQR) & $20.0(2.2)$ & $20.0(2.3)$ & $20.1(2.1)$ \\
\hline Age at end of follow-up, range & $19-101$ & 20-99 & 19-101 \\
\hline Age at end of follow-up, median (IQR) & $60.8(24.1)$ & $60.7(24.4)$ & $60.9(23.8)$ \\
\hline
\end{tabular}

regarded as complete for the entire Norwegian population since 1 January 1951. Information on vital status, emigration and date of death and emigration was provided by the National Registry. The linkage was based on the 11-digit unique personal identification number given to all citizens of Norway alive in 1960 or born thereafter. Those who died between 1951 and 1960 were identified by name and date of birth. Deaths in the register were recorded according to the International Classification of Diseases (ICD), 6th (through 1957), 7th (1958-1968), 8th (1969-1985), 9th (1986-1995) and 10th (1996-2017) revisions, and grouped according to the European Shortlist for causes of death (65 key causes). ${ }^{15} 16$ The shortlist codes were designed for comparison over time and between regions. ${ }^{17}{ }^{18}$ In the current study, all deaths are expressed as ICD-10 codes.

All servicemen were followed from their first day of recorded service in the Navy, but no earlier than 1 January 1951, until emigration, death or end of follow-up (31 December 2017). Median age of the cohort members was 20.0 years (IQR 2.2) at start of follow-up.

\section{Statistical analysis}

Standardised mortality ratios (SMRs) were calculated as ratios of observed and expected numbers. Because mortality rates vary by age, by sex and over time, the expected annual number of deaths among servicemen was derived by multiplying the 5 years age-specific person-years for servicemen by the corresponding Norwegian national pooled mortality rates for men. We calculated SMRs for all causes combined, for neoplastic and non-neoplastic diseases separately and for external causes for the entire follow-up period and for seven successive follow-up periods for each serviceman $(0-9,10-19,20-29,30-39,40-49$, $50-59$ and $\geq 60$ years). This was performed for the overall cohort and for the duty station subgroups of land-based personnel and vessel crews separately. Poisson regression analysis was used to compare all-cause mortality rates between the two subgroups, with observation period and age included in the models. Relative risks, expressed as rate ratios (RRs), were calculated for vessel crews, using land-based personnel as the reference category. A 
two-sided $\mathrm{p}<0.05$ indicated statistical significance, and 95\% CIs were computed based on the assumption of a Poisson distribution of the observed deaths. Stata V.15 (StataCorp) was used for statistical analyses and to create the figures. Of the total deaths, 428 were from unknown causes, including 172 with entries of ill defined and unknown causes of mortality (ICD-10 codes R96-R99). The remaining 256 cases were categorised as being from unknown causes due to lack of information. According to the Cause of Death Registry of Norway, half of such deaths occurred abroad. ${ }^{19}$ The 428 deaths from unknown causes constituted $6.9 \%$ of all deaths in the cohort $(6.8 \%$ in land-based personnel and $7.0 \%$ in vessel crews) and were included in allcause mortality analyses but excluded from the disease-cause and external-cause SMRs.

\section{RESULTS}

A total of 1121849 person-years and 6191 deaths were accumulated during the entire, 67years follow-up period (19512017). Half of the deaths-3064-were from non-neoplastic diseases, 2168 from neoplastic diseases and 530 from external causes. Two hundred and twenty-five servicemen were followed throughout the entire period, and average follow-up was 39.6 years.

\section{Overall cohort}

When the entire follow-up period was considered, all-cause mortality was $16 \%$ lower than expected $(\mathrm{SMR}=0.84,95 \% \mathrm{CI}$ 0.82 to 0.86 ). Low mortality from external causes $(\mathrm{SMR}=0.65$, $95 \% \mathrm{CI} 0.60$ to 0.71 ) and from non-neoplastic diseases $(\mathrm{SMR}=0.76,95 \% \mathrm{CI} 0.73$ to 0.79$)$ contributed to the low allcause mortality, while cancer mortality was close to national rates $(\mathrm{SMR}=0.98,95 \% \mathrm{CI} 0.93$ to 1.02$)$ (figure 1 and online supplementary table). The 428 deaths from unknown causes showed elevated mortality rates in the total cohort $(\mathrm{SMR}=1.54$, $95 \%$ CI 1.40 to 1.70$)$, in land-based personnel $(\mathrm{SMR}=1.34)$ and in vessel crews $(\mathrm{SMR}=1.71)$.

The all-cause mortality deficit fell during follow-up in a near linear manner. A statistically significant deficit was observed for all but the last follow-up period ( $\geq 60$ years, $S M R=0.93,95 \% \mathrm{CI}$ 0.86 to 1.01 ) (figure 2 and online supplementary table). Low mortality from non-neoplastic diseases contributed the most to the longevity of the overall HSE. The mortality for this category increased rather steeply from one-third $(\mathrm{SMR}=0.38,95 \% \mathrm{CI}$ 0.27 to 0.51$)$ to two-thirds $(\mathrm{SMR}=0.69,95 \% \mathrm{CI} 0.58$ to 0.81$)$ of national rates during the first two 10 -year follow-up periods. Thereafter they increased gradually, but statistically significant mortality reduction was still present after 60 years $(\mathrm{SMR}=0.87$,

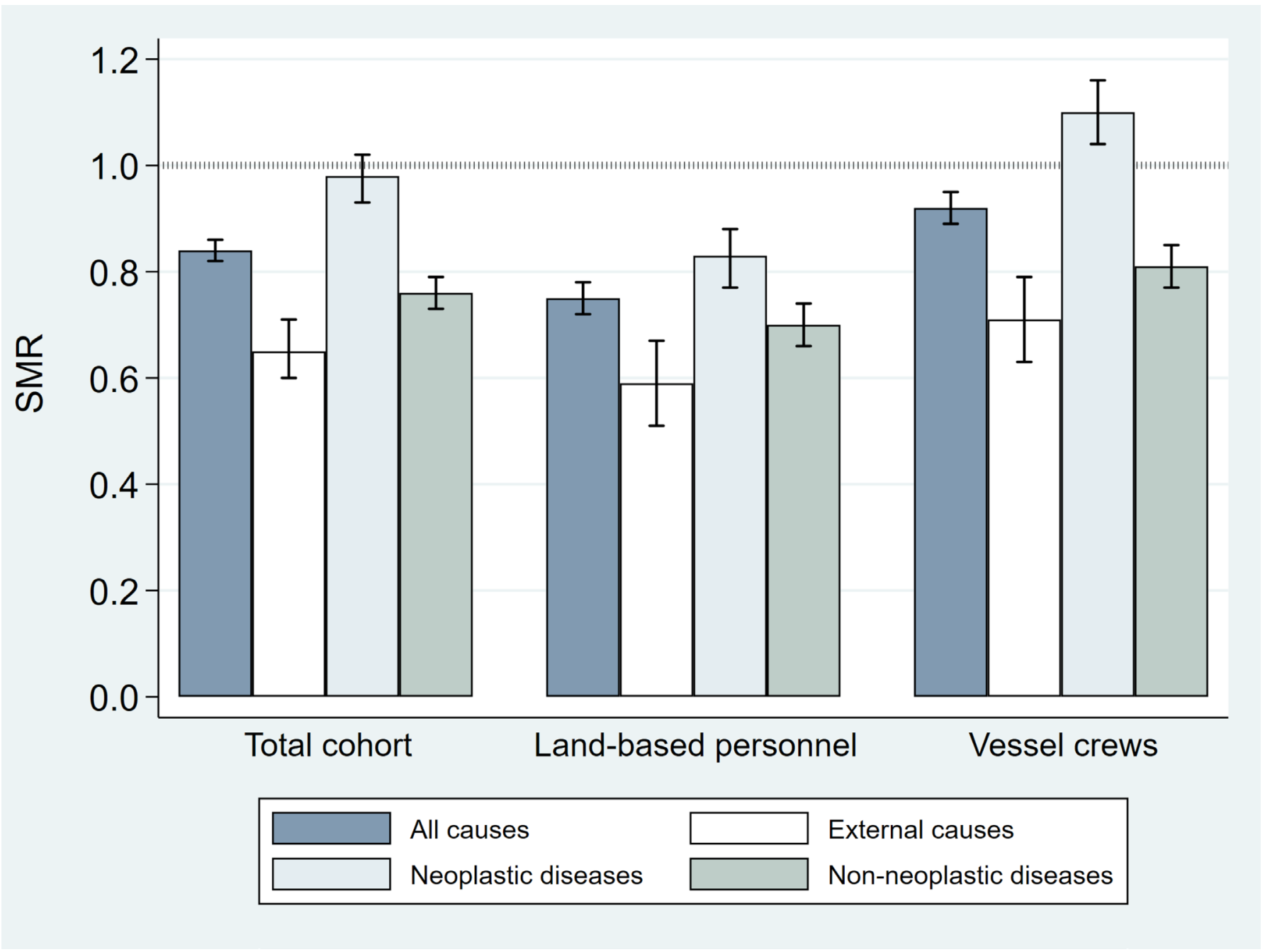

Figure 1 Standardised mortality ratios (SMRs) with 95\% confidence intervals (CIs) for the overall cohort ( $n=28349,1121849$ person-years) and for subgroups of land-based personnel ( $n=12$ 943, 507561 person-years) and vessel crews ( $n=15406,614287$ person-years) separately. Follow-up 1951 2017. 

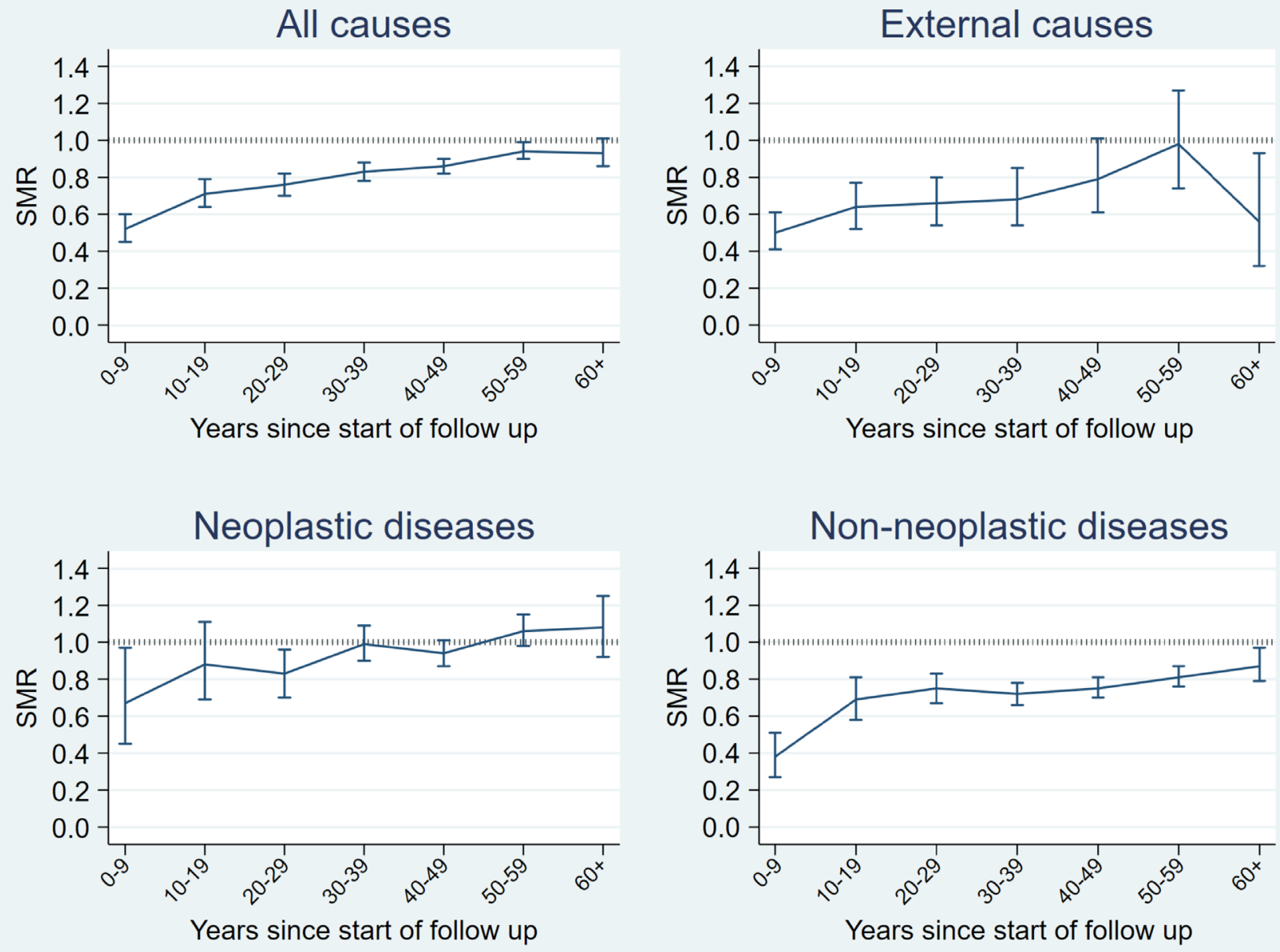

Figure 2 Standardised mortality ratios (SMRs) by follow-up period with 95\% confidence intervals (CIs) for the overall cohort. Follow-up $1951-2017$.

95\% CI 0.79 to 0.97). For neoplastic diseases, the temporal change in relative mortality was less linear: there was a statistically significant mortality deficit only for the first $(\mathrm{SMR}=0.67$, $95 \% \mathrm{CI} 0.45$ to 0.97$)$ and third $(\mathrm{SMR}=0.83,95 \% \mathrm{CI} 0.70$ to 0.96) 10 -year follow-up periods. In the subsequent follow-up periods, neoplastic mortality rates were similar to national rates. External-cause mortality ratios rose gradually, starting at half that of national rates during the first 10-year follow-up period and reaching the population average after 40 years. After 60 years of follow-up, the SMR dropped back to a statistically significant mortality reduction.

\section{Mortality by duty station subgroup}

Compared with national rates, land-based personnel showed mortality reductions for all causes, neoplastic diseases, nonneoplastic diseases and external causes during the entire follow-up period (figure 1 and online supplementary table). Among vessel crews, we observed general mortality reductions for all causes, non-neoplastic diseases and external causes, while neoplasticdisease mortality was significantly elevated (SMR $=1.1095 \% \mathrm{CI}$ 1.04 to 1.16). Poisson regression showed that vessel crews had a statistically significant, higher total mortality risk than landbased personnel (RR 1.24, 95\% CI 1.18 to 1.30 ).

The temporal mortality pattern in the two duty station subgroups was quite similar to that of the overall cohort, but the HSE was stronger and lasted longer among land-based personnel than in vessel crews. While a mortality reduction for all causes was still present after 60 years of follow-up in landbased personnel, it only lasted up to 50 years among vessel crews (figure 3 and online supplementary table). For cancer, we saw a mortality reduction in land-based personnel in the first 10 -year follow-up period $(\mathrm{SMR}=0.44)$, no reduction in the second 10 -year follow-up period $(\mathrm{SMR}=0.93)$, and thereafter it shifted between reduction and unity. Among vessel crews on the other hand, cancer mortality rates were on a par with national rates during the first 50 years, followed by an excess in cancer mortality. In both duty station subgroups, we saw mortality reduction for non-neoplasms throughout all follow-up periods. The mortality reduction for external causes lasted up to 40 years in both duty station subgroups.

\section{DISCUSSION}

To our knowledge, ours is the first study to follow a military cohort through successive follow-up periods for more than 60 years, where the last interval covered the years 60-67 since start of follow-up. Our cohort members entered the cohort at a relatively young age during a period of more than half a century. The analyses might have been subjected to a 'cohort effect', that is, the variation in the risk of a health outcome according to the year of birth, which might coincide with variation in the population 
All causes

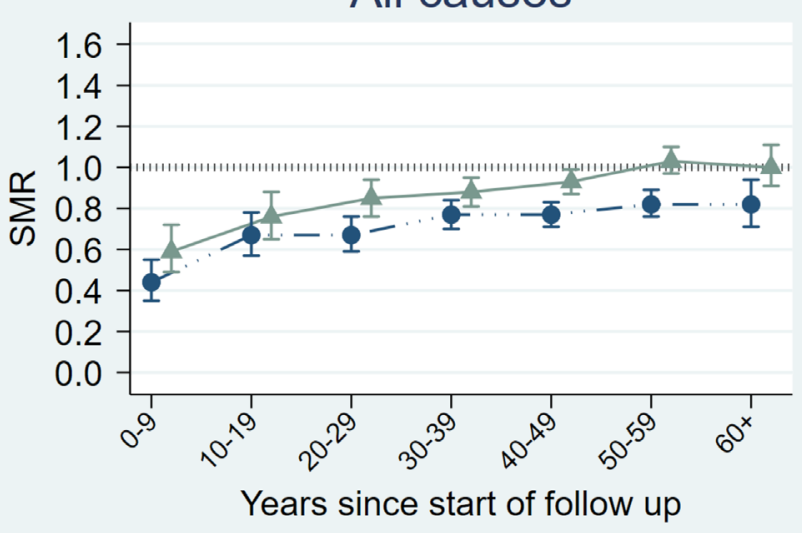

Neoplastic diseases

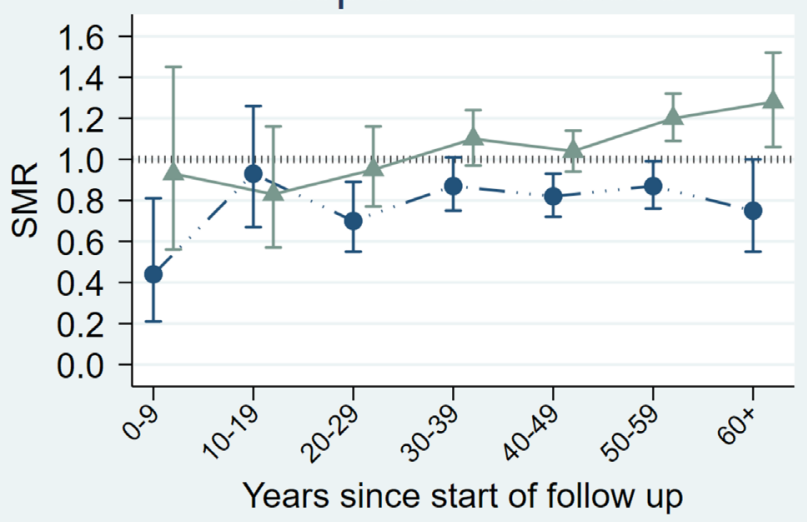

External causes

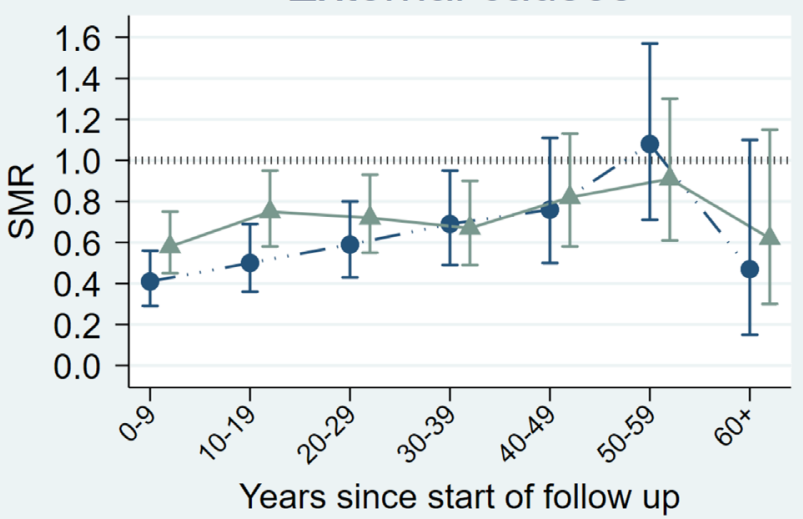

Non-neoplastic diseases

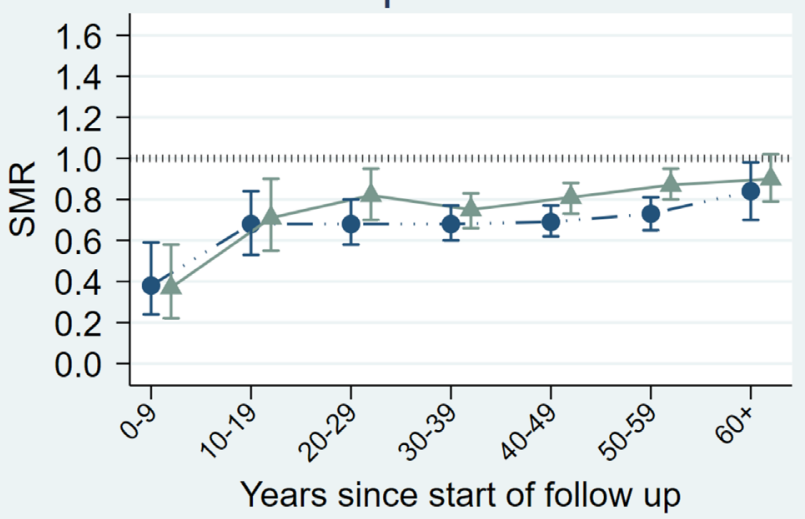

- - Land-based personnel $\_$Vessel crews

Figure 3 Standardised mortality ratios (SMRs) by follow-up period with 95\% confidence intervals (Cls) for the duty station subgroups of land-based personnel and vessel crews separately. Follow-up 1951-2017.

exposure to risk factors over time. ${ }^{20}$ In our analyses, the cohort was followed up dynamically during time, multiplying personyear at risk stratified in 5-year age and 1-year period categories, with the corresponding age-specific and period-specific mortality rates. This ensures that the effect of period is incorporated in the SMRs and the cohort effect should be minimised.

In addition to the length of follow-up, the strengths of this study include a military cohort that is virtually complete. Moreover, positive identification of cohort members in high-quality cause-of-death and national population registries should secure reliable and unbiased estimates. We had no lost to follow-up, except from emigration at specified dates, and at end of the study period, we knew who had died and who had emigrated. Study weaknesses include lack of information on factors that may influence cohort members' longevity, such as hazardous occupational exposures inside and outside the Navy, and data on lifestyle factors such as tobacco smoking, alcohol consumption and physical activity. Such data could help explain the observed difference in mortality between our two duty station subgroups, as the land-based group showed stronger and longer-lasting HSE than did vessel crews.

We chose to look at broad categories of causes of death to ensure statistical power for calculation of SMRs across two subgroups over seven successive time intervals. The broad categorisation and the use of shortlist codes should minimise the problem with changes in classification of deaths over time. No deaths were moved between the categories of neoplasms and non-neoplasms in the course of the follow-up. ${ }^{16}$ However, from 2003, acute intoxication deaths in substance abusers were moved from the ICD-10 chapter 'Mental and behavioural disorders' to the category for accidental poisoning. ${ }^{162122}$ Six cohort deaths from intoxication after 2003 which would previously have been ascribed to non-neoplasms have now been moved to the category external causes. As those deaths constitute only $0.1 \%$ of all deaths in our cohort, the change is considered as having no significant effect on the results.

The exclusion of individuals with an unknown cause of death from cause-specific mortality estimates might have biased our results as the SMR in the overall cohort was reduced from 0.84 to 0.82 . However, we believe this reduction is too small to induce shifts in statistical significance in the disease-cause and external-cause SMRs and is judged to be of minor importance for our results.

As the median age at start of follow-up was 20 years, the cohort members were aged 80 years or older during the last follow-up period. This is indicative of the effectiveness of the HSE among older populations, and is probably due to the maintenance of a healthy lifestyle that involves physical activity. Indeed, one study found that, compared with individuals who were not active at age 40 years, those who were active were twice as likely to 
remain active at older ages ${ }^{23}$ which is probably applicable to our cohort members. Several studies have shown a positive association between physical activity and reduced all-cause mortality in elderly people. ${ }^{23-27}$ Paganini-Hill et al found significant reduction in mortality among men aged $70-74,75-79$ and $\geq 80$ years who participated in less physically demanding activities as well as traditional physical activities involving moderate exertion. ${ }^{23}$ Physical activity prevents mortality by reducing the incidence of cardiovascular risk factors, such as type 2 diabetes and hypertension, by weight reduction, and by prevention of falls, osteoporosis and mobility disability. ${ }^{27-30}$

Low mortality from non-neoplastic diseases in our cohort is in accordance with studies comprising veterans from the Second World War (calculated from data in Seltzer and Jablon) ${ }^{12}$ and peacekeepers deployed to Lebanon during 1978-1998. ${ }^{13}$ Indeed, overall fitness is evaluated by the draft board before compulsory military service, and persons with chronic illnesses are excluded. The demand to stay physically fit during service probably reduces the risk of mortality from cardiovascular diseases, respiratory diseases and diseases of the digestive system, a reduction shown in the previous study on our cohort members $(\mathrm{SMR}=0.86,0.74$ and 0.81 , respectively, follow-up 1951-2007). ${ }^{6}$ The relatively short duration of HSE from cancer mortality in our study is also in line with the above-mentioned studies on veterans from war and peacekeeping service. As cancers might be caused by random mutations, ${ }^{31}$ and factors that predict eventual death from cancer are less likely to be present at 20 years of age than factors that may predict deaths from other causes, ${ }^{32}$ the short-lived HSE in our study is probably due to a demand to be cancer-free at start of service.

When we looked at mortality by duty station subgroup, the HSE was present among vessel crews for all causes, external causes and diseases (except from cancer mortality, which was elevated), but the rates were not as low as in land-based personnel. As both personnel groups had to pass a medical screening for military service, the difference might be due to the work environment on seafaring vessels, which may be more hazardous with respect of harmful chemical exposure and accidents than that of landbased installations. For instance, asbestos was used aboard Navy vessels for insulation and fireproofing in a manner that could potentially put the entire crew at risk of exposure before the compound was removed during the mid-1980s. Using excess malignant mesothelioma as an indicator of asbestos exposure, the risk was found to be confined to marine engine crews only. ${ }^{33}$ We also assume that self-selection and lifestyle plays a role, as conscripts as well as military careerists, can choose between military branches and duty stations. The previous study on this same cohort showed that vessel crews had a higher risk of lung cancer and alcohol-related cancers, and higher mortality from diseases of the circulatory system and non-neoplastic alcohol diseases than land-based personnel and concluded that the differences could be partly due to differences in the consumption of alcohol and tobacco. ${ }^{6}$

\section{CONCLUSION}

Our study showed that the HSE eroded gradually over time but was still present at 60 years of follow-up in the overall cohort and in the land-based duty station subgroup, which means that HSE persists in older age groups. The effect was strongest and most long-lived for non-neoplastic disease, lasted up to 40 years for external causes, and was relatively short for cancers. Landbased personnel showed stronger and longer-lasting HSE than vessel crews.
Acknowledgements We want to acknowledge Trudy Perdrix-Thoma, Professional Standards Editing for language editing assistance.

Contributors LAS and EKB designed the study. JIM performed the statistical analyses, and quality control of data and algorithms was performed by JIM and LAS. LAS wrote the first draft of the manuscript and is the guarantor of the manuscript. The Figures were created by EAF. All authors interpreted the data and revised the manuscript carefully. All authors approved the final version of the manuscript, and LAS had the final responsibility to submit the manuscript.

Funding This study was funded by the Norwegian Armed Forces Joint Medical Services.

Competing interests None declared.

Patient consent for publication Not required.

Ethics approval The present study was approved by the Regional Committees for Medical Health Research Ethics of Southern Norway. Data used in our study are retrieved from national health registries in Norway. The registries were established by the Norwegian government and contains personal identifiable information that are not based on consent. The registries are regulated according to the Health Register Act.

Provenance and peer review Not commissioned; externally peer reviewed.

Data availability statement Data are available on reasonable request. The data that support the findings of this study are available from The Norwegian Armed Forces Health Registry but restrictions apply to the availability of these data, which were used under license for the current study, and so are not publicly available. Data are however available from the authors on reasonable request and with permission of The Norwegian Armed Forces Health Registry.

\section{ORCID iD}

Leif Aage Strand http://orcid.org/0000-0002-8486-0272

\section{REFERENCES}

1 McMichael AJ, Spirtas R, Kupper LL. An epidemiologic study of mortality within a cohort of rubber workers, 1964-72. J Occup Med 1974;16:458-64.

2 Kang HK, Bullman TA. Mortality among U.S. veterans of the Persian Gulf War. N Eng/ J Med 1996;335:1498-504

3 McLaughlin R, Nielsen L, Waller M. An evaluation of the effect of military service on mortality: quantifying the healthy soldier effect. Ann Epidemiol 2008;18:928-36.

4 Erratum. Ann Epidemiol 2015;25:143.

5 Waller M, McGuire ACL. Changes over time in the "healthy soldier effect". Popul Health Metr 2011;9:7.

6 Strand LA, Martinsen JI, Koefoed VF, et al. Cause-Specific mortality and cancer incidence among 28300 Royal Norwegian navy servicemen followed for more than 50 years. Scand J Work Environ Health 2011;37:307-15.

7 Strand LA, Martinsen JI, Borud EK. Cancer risk and all-cause mortality among Norwegian military United nations peacekeepers deployed to Kosovo between 1999 and 2011. Cancer Epidemiol 2014;38:364-8.

8 Strand LA, Martinsen JI, Borud EK. Cancer incidence and all-cause mortality in a cohort of 21582 Norwegian military peacekeepers deployed to Lebanon during 1978-1998. Cancer Epidemiol 2015:39:571-7.

9 McBride D, Cox B, Broughton J, et al. The mortality and cancer experience of new Zealand Vietnam war veterans: a cohort study. BMJ Open 2013;3:2013-003379.

10 Rolland-Harris E, Weeks M, Simkus K, et al. Overall mortality of Canadian armed forces personnel enrolled 1976-2012. Occup Med 2018;68:32-7.

11 Fox AJ, Collier PF. Low mortality rates in industrial cohort studies due to selection for work and survival in the industry. Journal of Epidemiology \& Community Health 1976;30:225-30.

12 Seltzer CC, Jablon S. Effects of selection on mortality. Am J Epidemiol 1974;100:367-72.

13 Strand LA, Martinsen JI, Borud EK. Disease-Related mortality among 21,609 Norwegian male military peacekeepers deployed to Lebanon between 1978 and 1998. Ann Epidemiol 2016;26:693-7.

14 Strand LA, Koefoed VF, Oraug TMT, et al. Establishment of the Royal Norwegian navy personnel cohorts for cancer incidence and mortality studies. Mil Med 2008;173:785-91.

15 European Shortlist for causes of death, 1998. Available: http://ec.europa.eu/ eurostat/ramon/nomenclatures/index.cfm?TargetUrl=LST_NOM_DTL_LINEAR\& IntCurrentPage $=2 \&$ StrNom $=$ COD_1998\&StrLanguageCode $=$ EN2018

16 Dødelighet og dødsårsaker i Norge gjennom 60 år 1951-2010 [Mortality and causes of death in Norway over 60 years 1951-2010] Oslo, Norway: Norwegian Institute of Public Health, 2012. Available: https://www.fhi.no/publ/2012/dodelighet-ogdodsarsaker-i-norge-g/

17 Kibele EUB. Regional mortality differences in Germany. Netherlands: Springer, 2012

18 Health statistics. - atlas on mortality in the European Union. Luxembourg: Office for Official Publications of the European Communities: Eurostat, European Commission, 2009. 
19 Cause of death statsistics bank: Norwegian cause of death registry, 2020. Available: http://statistikkbank.fhi.no/dar/ [Accessed 11 Apr 2020].

20 Keyes KM, Utz RL, Robinson W, et al. What is a cohort effect? comparison of three statistical methods for modeling cohort effects in obesity prevalence in the United States, 1971-2006. Soc Sci Med 2010;70:1100-8.

21 Gjertsen F, Bruzzone S, Vollrath ME, et al. Comparing ICD-9 and ICD-10: the impact on intentional and unintentional injury mortality statistics in Italy and Norway. Injury 2013:44:132-8

22 Kodebok Dødsårsaksregisteret 1951-2004 [Codebook for the Norwegian Cause of Death Registry 1951-2004] Oslo, Norway: Norwegian Institute of Public Health, 2007. Available: www.fhi.no ' dar ' kodebok-dodsarsaksregisteret-1951-2004-pdf

23 Paganini-Hill A, Kawas CH, Corrada MM. Activities and mortality in the elderly: the leisure world cohort study. J Gerontol A Biol Sci Med Sci 2011;66:559-67.

24 Llamas-Velasco S, Villarejo-Galende A, Contador I, et al. Physical activity and longterm mortality risk in older adults: a prospective population based study (NEDICES). Prev Med Rep 2016;4:546-50.

25 Ueshima K, Ishikawa-Takata K, Yorifuji T, et al. Physical activity and mortality risk in the Japanese elderly. Am J Prev Med 2010;38:410-8.

26 Wu C-Y, Hu H-Y, Chou Y-C, et al. The association of physical activity with all-cause, cardiovascular, and cancer mortalities among older adults. Prev Med 2015;72:23-9.
27 Haskell WL, Lee I-M, Pate RR, et al. Physical activity and public health: updated recommendation for adults from the American College of sports medicine and the American heart association. Med Sci Sports Exerc 2007;39:1423-34.

28 , Grossman DC, Curry SJ, et al, US Preventive Services Task Force. Interventions to prevent falls in community-dwelling older adults: US preventive services Task force recommendation statement. JAMA 2018;319:1696-704.

29 Nelson ME, Rejeski WJ, Blair SN, et al. Physical activity and public health in older adults: recommendation from the American College of sports medicine and the American heart association. Med Sci Sports Exerc 2007;39:1435-45.

30 Murtagh EM, Nichols L, Mohammed MA, et al. The effect of walking on risk factors for cardiovascular disease: an updated systematic review and meta-analysis of randomised control trials. Prev Med 2015;72:34-43.

31 Tomasetti C, Vogelstein B. Variation in cancer risk among tissues can be explained by the number of stem cell divisions. Science 2015;347:78-81.

32 Monson RR. Observations on the healthy worker effect. J Occup Environ Med 1986;28:425-33.

33 Strand LA, Martinsen JI, Koefoed VF, et al. Asbestos-Related cancers among 28,300 military servicemen in the Royal Norwegian navy. Am J Ind Med 2010;53:64-71. 